\title{
Feminino Sagrado, Profano e Científico: impasses nas intervenções genitais femininas $^{1}$
}

\author{
Claudia Fioretti Bongianino ${ }^{2}$ \\ Denise Ferreira da Costa $\mathrm{Cruz}^{3}$ \\ Luísa Reis de Castro ${ }^{4}$
}

\section{Resumo}

O que acontece quando o direito de minorias étnicas e religiosas parece ser incompatível com o direito nacional, os direitos humanos internacionais e os direitos das mulheres? Pensar tal questão é o objetivo deste trabalho, que foca no impasse em torno das Intervenções Genitais Femininas (IGF). Partindo da definição de Mutilação Genital Feminina (MGF), fornecida pela Organização Mundial de Saúde (OMS) em 1997, busca-se analisar a construção do conceito de MGF, assim como o impacto das legislações e das políticas públicas estabelecidas a partir dele. Para tanto, as autoras tomam como caso de estudo a Itália, um

${ }^{1} \mathrm{O}$ presente artigo é fruto de uma pesquisa iniciada em 2008, por Claudia Fioretti Bongianino e conduzida em parceria com Luísa Reis de Castro e Denise Ferreira da Costa. Luísa participou da análise e interpretação dos dados e da redação de uma primeira versão do manuscrito, durante a primeira etapa da pesquisa em 2009. Entre 2010 e 2015, foram coletados ulteriores dados. Nessa segunda fase da pesquisa, Denise participou da análise e interpretação do conjunto completo dos dados, assim como da revisão e aprovação da versão final a ser publicada. Claudia Fioretti Bongianino participou de todas as etapas da pesquisa e da elaboração do manuscrito. As três autoras assumem publicamente a responsabilidade pelo conteúdo do artigo.

${ }^{2}$ Museu Nacional, Universidade Federal do Rio de Janeiro (MN/ UFRJ, Brasil). Doutoranda no Programa de Pós Graduação em Antropologia Social (PPGAS/ MN/ UFRJ) E-mail: fioretti.claudia@gmail.com

${ }^{3}$ Universidade de Brasília (UnB, Brasil). Doutoranda no Programa de Pós Graduação em Antropologia Social (PPGAS/ UnB, Brasil). E-mail: deniseklaxon@gmail.com.

${ }^{4}$ Massachusetts Institute of Technology (MIT, EUA). Doutoranda no Programa de Pós Graduação em História, Antropologia, e Estudos da Ciência, Tecnologia, e Sociedade, Massachusetts Institute of Technology, (HASTS/MIT, EUA). E-mail: luisarc@mit.edu. 
dos países com maior índice de MGF. Paralelamente, realizamos uma reflexão acerca das diversas formas de IGF (MGF, Circuncisão Feminina, Cirurgia de Correção de Genitália, Cirurgia 'Cosmética' Genital Feminina), com o intuito de compreender o que há (ou não) de violento em cada tipo de IGF.

Palavras-chave: Mutilação Genital Feminina; Antropologia do Gênero; Direitos Humanos.

\section{Sacred, profane and scientific womanhood: impasses concerning female genital interventions}

Abstract

What happens when the rights of (religious and ethnic) minorities seem to be not compatible with national \& international laws, or with women's rights? This paper aims to think critically about this question, by analyzing the impasse about Female Genital Interventions (FGI). Based on the definition of Female Genital Mutilation (FGM) given by the World Health Organization (WHO) in 1997, the authors try to understand the construction of this concept as well as the impact of the creation of legislations and policies referring to FGM. In order to do so, we take Italy as a case study, since it is one of the countries with highest levels of FGM. At the same time, we critically review different kinds of FGI (FGM, Female Circumcision, Surgery of Genitalia Correction, Female Genital 'Cosmetic' Surgery), putting them together, in order to look for what is (or not) violent in each one of them.

Keywords: Female Genital Mutilation; Anthropology of Gender; Human rights. 


\section{Introdução}

O encontro entre lógicas e práticas culturais distintas (acarretado por viagens, migrações ou informações veiculadas pela mídia globalizada) traz à tona uma série de conflitos relacionados à conciliação entre morais diferentes. No caso das práticas denominadas de Mutilação Genital Feminina (MGF) ${ }^{5}$, esse encontro coloca em disputa interpretações sobre corpo, gênero, violência, dignidade e religião. Por um lado, trata-se de práticas culturais tradicionais realizadas por pessoas (residentes em ou provenientes de) diversos contextos islâmicos do continente africano, práticas essas que correspondem a importantes ritos por meio dos quais meninas passam a ser mulheres, tornando-se boas esposas e mães. Por outro lado, essas práticas são permeadas por dimensões chocantes e violentas, sendo criminalizadas pela legislação e combatidas através de políticas públicas e movimentos sociais, uma vez que elas ameaçam a saúde da mulher (podendo causar infecções, problemas psicológicos, doenças e mortes) e podem lesar sua qualidade de vida (limitando seu prazer sexual genital) ${ }^{6}$.

${ }^{5} \mathrm{O}$ termo Mutilação Genital Feminina e sua sigla (MGF) serão usados alternativamente ao longo do texto, para tornar o texto mais fluido, reduzir repetições. 0 mesmo procedimento será adotado em relação aos seguintes termos e siglas: Intervenção Genital Feminina (IGF), Circuncisão Feminina (CF), Cirurgia de Correção de Genitália (CCG) e Cirurgia 'Cosmética' Genital Feminina (CCGF).

${ }^{6}$ Embora a discussão sobre o prazer sexual genital seja central no debate entorno da Mutilação Genital Feminina (MGF), ela não será analisado a fundo no presente artigo, uma vez que ele parte da definição de MGF fornecida pela Organização Mundial de Saúde (WHO, 1997). Como será detalhado adiante, essa definição se funda sobre uma oposição entre 'razões culturais' e 'fins terapêuticos', a qual deixa de lado a dimensão do prazer. Por outro lado, exatamente por essa definição focar nas razões culturais e fins terapêuticos, foi possível incluir, na presente análise, outras práticas de intervenção genital feminina marcadas por essa oposição - a saber as práticas denominadas de Circuncisão Feminina (CF), Cirurgia de Correção de Genitália (CCG) e Cirurgia 'Cosmética' Genital Feminina (CCGF). Focando sempre nessa oposição entre razões culturais e fins terapêuticos, de outro, seria possível inserir na análise práticas ulteriores - por exemplo -, as cirurgias genitais realizadas por transexuais. Provavelmente, investigar outras práticas por meio de um exercício análogo ao realizado neste texto teria rendimentos interessan- 
Periodicamente, reportagens comemoram a "criminalização da Mutilação Genital Feminina” (MGF) em países do continente africano, europeu ou americano. Vários grupos ativistas do Brasil e do mundo (movimento feminista, movimento negro, ONGs de defesa dos direitos humanos etc.) veiculam essas notícias (em suas redes sociais, páginas na web etc.) como uma conquista das mulheres negras de todo o mundo e dos seres humanos em geral. Geralmente, o ponto acriticamente universalizado por essas notícias é que a prática da MGF é uma violência contra os direitos das mulheres e os direitos humanos universais, pois é uma expressão da dominação de gênero (da submissão feminina e da opressão masculina), além de ser uma manifestação de fundamentalismo religioso, de coerção social etc.

Neste artigo, busca-se refletir sobre essa abordagem universalista das práticas denominadas de MGF, questionando se a criminalização seria a medida mais adequada para lidar com as dimensões violentas presentes nestas práticas. Ao perseguir tão objetivo, porém, o presente texto procura adotar uma abordagem que não seja particularista, de cunho relativista - opondo-se a criminalização das práticas denominadas de MGF por argumentar que elas são legitimadas pela lógica cultural tradicional na qual elas estão inseridas. Diferentemente, o artigo adota a perspectiva desenvolvida pela antropologia feminista e foca no princípio metodológico da posição diferenciada dos agentes (ZANOTTA MACHADO, 2013). De fato, opiniões favoráveis ou contrárias à criminalização das práticas denominadas de MGF não são compartilhadas por toda a cultura onde elas são realizadas (como postularia o relativismo cultural). Diferentemente, elas são debatidas entre os homens e as mulheres, de diferentes idades, que a realizam ou não, em diferen-

tes. Igualmente interessante poderia ser a realização de um estudo detalhado acerca da relação entre todas essas práticas e o prazer - refletindo inclusive sobre o prazer não localizado na região genital e sobre o prazer não sexual. Estas possibilidades ficam em aberto para pesquisas futuras. 
ciados contextos (conforme ensina o princípio metodológico da posição diferenciada dos agentes). Assim, a pergunta que aparece como central é: quem, por que e quando concorda ou discorda com a criminalização da MFG?

A resposta para tal pergunta é extremamente complexa e demanda cuidadosas reflexões capazes de dar voz à vivência das mulheres e dos homens que ocupam diferentes posições em relação à MGF (inclusive em diferentes momentos da vida de cada pessoa em questão). Embora essa necessária abordagem etnográfica fuja às possibilidades do presente artigo, ele tem como objetivo responder a uma pergunta análoga: como, quando e por que a prática denominada de MGF é, ou não, uma violência? Essa pergunta é motivada por uma inquietação comum às três autoras deste texto: não nos parece possível adotar um posicionamento favorável ou contrário à criminalização da MGF, sem produzir novas violências. Certamente somos favoráveis ao combate dos aspectos violentos da MGF, mas a pergunta que nos inquieta é: somos favoráveis à criminalização da MGF? A própria denominação dessas práticas de MGF não teria o efeito perverso de taxar os corpos de inúmeras mulheres como mutilados? Concluir apressadamente que essas mulheres são vítimas de uma violência (de uma dominação de gênero, de uma coerção cultural e religiosa) não poderia implicar em tratá-las sempre e apenas como vítimas, em privá-las de agência e em alienar sua capacidade de pensamento autônomo? A criminalização das práticas denominadas de MGF não teria o efeito perverso de tornar ainda mais vulnerável a posição das mulheres que as realizam? A criminalização não dificultaria seu acesso a hospitais (para tratamento ou acompanhamento ginecológico e obstétrico), pois correriam o risco de serem denunciadas e presas (junto com seus parentes que realizaram a MGF em seus corpos, muitas vezes suas mães)?

Ao invés de paralisar-se perante o impasse posto por essa inquietação, o presente texto visa explorá-lo através da janela 
analítica aberta por uma intuição que tivemos e que se revelou particularmente fértil: para entender os aspectos violentos da MGF, não basta olhar para ela; para compreendê-los, é fundamental atentar para outras práticas que também poderiam ser denominadas de MGF, mas não são - como a Cirurgia de Correção de Genitália (CCG) e a Cirurgia 'Cosmética' Genital Feminina (CCGF) ${ }^{7}$. Conforme será detalhado ao longo do texto, essa intuição permite deslocar o impasse inerente à MGF e posicionar-se perante ele. De fato, ao pautar a análise nessa intuição, é possível refletir sobre o fenômeno das Intervenções Genitais Femininas (IGF) - o qual inclui a MGF -, mas não se limita a ela. Dessa forma, parece possível deixar de estigmatizar sempre e apenas práticas exóticas, abrindo os olhos para violências análogas à da MGF (embora menos exóticas), as quais acabam sendo legitimadas, por não serem problematizadas.

Essa aproximação entre práticas diferentes englobadas todas sob o termo Intervenção Genital Feminina, tem como finalidade explorar as semelhanças e diferenças entre elas, sem colocá-las no mesmo plano, mas sim pensando cada uma em relação às outras. Ao proceder dessa maneira, torna-se possível explicitar o caráter construído e historicamente datado dessas terminologias - correspondentes todas as generalizações realizadas a partir da complexidade e diversidade das práticas nativas. Destarte, procura-se compreender o que há (ou não) de violento em cada uma delas e, assim, propor soluções teóricas e empíricas para a difícil conciliação entre os universalismos e os particularmos que permeiam o debate em torno da prática denominada de $\mathrm{Mu}$ tilação Genital Feminina.

\footnotetext{
${ }^{7}$ Ao longo do texto, serão reportados entre 'aspas simples' as expressões que corresponderem usos teóricos ou nativos específicos, assim como os termos em língua estrangeira.
} 


\section{Construção da CF, M GF e IGF}

Variadas formas de intervenções nos órgãos genitais femininos praticadas por diferentes populações africanas são conhecidas por pessoas que residem fora do continente africano ao menos desde a era colonial, quando foram denominadas de Circuncisão Feminina (CF), passando a englobar os diferentes nomes nativos atribuídos ela (LIGHTFOOT-KLEIN, 1989). Generalizando, a Circuncisão Feminina pode ser descrita como um ritual de iniciação, praticado por sociedades secretas femininas, no contexto de variantes da religião muçulmana, presentes sobretudo na faixa do Sahel do continente africano.

Sociedades secretas são congregações de pessoas por faixa etária e gênero. A maioria delas está presente na região da Libéria e de Serra Leoa, onde as mais renomadas são 'Poro' - sociedade secreta masculina estudada por Kenneth Little (1965) - e 'Sande' - sociedade secreta feminina pesquisada por Carol MacCormack (1979). Essas sociedades secretas originam formas institucionalizadas de agrupamentos sociais e estão associadas aos rituais de iniciação, que geralmente incluem a circuncisão (masculina e feminina). Tais rituais fornecem a educação necessária para se alcançar a maturidade pessoal e social, possibilitando o casamento, o reconhecimento da prole e o acesso à terra. Essa entrada ritual no mundo adulto corresponde a um processo doloroso, o qual é enfrentado coletivamente, sendo a dor sanada pela medicina sagrada - cujo conhecimento é secreto e monopolizado pelos membros da alta hierarquia das sociedades secretas.

Enquanto ritual praticado por sociedades secretas femininas, a Circuncisão Feminina (CF) é um segredo ritual que diz respeito apenas ao mundo feminino, sendo realizada em mulheres e por mulheres. A CF determina uma mudança no 'status', isto é, na posição social das mulheres iniciadas, podendo integrar um conjunto de cerimônias, distribuídas ao longo de semanas. Por meio dessas cerimônias, as jovens iniciadas aprendem seu papel 
de mulher, esposa e mãe, além de mostrarem que são capazes de assumir corajosamente um novo papel, sem manifestar sinais de sofrimento ou de dor e sem revelar nada do que se passou durante as cerimônias. Assim, as mulheres tornam-se "preciosas", assumem sua identidade e mantêm sua pureza, sendo a Circuncisão Feminina condição necessária para entrar no mundo dos adultos e tornar-se mulher:

Nessas sociedades islâmicas africanas, a simplificação da identificação dos papéis se dava, e ainda hoje se dá, por meio de um modo aparentemente mais coerente, isto é, por meio da remoção cirúrgica das partes do corpo masculino (prepúcio) e feminino (clitóris) que não são reconhecidas como atributos do próprio gênero (LA MONACA et al., 2004, p. 647) ${ }^{8}$.

Nesses contextos é exatamente a manipulação física do corpo a estabelecer as relações entre os sexos e entre as gerações, por meio de uma estética de pureza, força e coragem. Vale notar que o percurso que leva à identificação de gênero não corresponde a uma manipulação física apenas nessas sociedades africanas. Em alguma medida, também nas sociedades ditas ocidentais, tal percurso é mais que metafórico e requer uma manipulação física - fato que se torna explícito no caso das Cirurgias de Correção Genitália (CCG) e da Cirurgia 'Cosmética' Genital Feminina (CCGF), apresentadas abaixo. Para aqueles que defendem a Circuncisão Feminina, uma menina/mulher que não tenha passado pela Circuncisão Feminina não seria considerada uma mulher de verdade, dotada de uma vagina 'normal', seria impura e não poderia se casar nem ter filhos, além de ser motivo de vergonha para sua família - ela seria, pois, isolada, marginalizada, enfim, privada de um futuro econômico, existencial e afetivo. Conforme será discutido adiante, porém, esses significados não são estáticos e, tal como todas as práticas culturais, estão abertos a reinterpretações por parte dos sujeitos sociais.

${ }^{8}$ Tradução das autoras do original em italiano. 
Por sua vez, o termo Mutilação Genital Feminina foi cunhado em 1997 pela Organização Mundial de Saúde (World Health Organization, WHO), sendo definido como "todos os procedimentos que envolvem a remoção parcial ou total dos órgãos genitais femininos ou que provoquem lesões nos mesmos, tendo por bases razões cul-

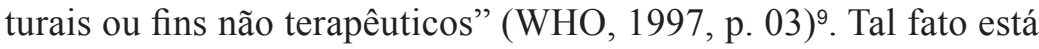
inserido num contexto internacional de grande pressão a favor da proibição das práticas que até então eram denominadas de Circuncisão Feminina (CF).

A prática denominada pela Organização Mundial de Saúde (OMS) de MGF normalmente corresponde à remoção do clitóris e à remoção parcial ou total dos pequenos lábios, mas pode corresponder também a formas mais brandas e também mais graves de intervenções: pode consistir em uma incisão sobre o prepúcio do clitóris ou na remoção desse prepúcio; pode corresponder à remoção total do clitóris e dos pequenos lábios, seguida da remoção total ou parcial dos grandes lábios e finalizada pela costura da vulva - de modo que o orifício vaginal seja fechado, deixando-se apenas um pequeno orifício para a passagem da urina e do sangue menstrual -; ou pode consistir ainda em punções do clitóris e/ou dos grandes lábios, em queimadura do clitóris e dos tecidos adjacentes, raspagem dos tecidos em torno do orifício vaginal, introdução de substâncias corrosivas ou de ervas na vagina - para causar sangramentos ou contrações (BOTTI, 2007).

A partir da década de 1980, essas práticas começam a ser fortemente condenadas, sendo vistas como danosas às funções sexuais femininas, à qualidade de vida da mulher, à sua dignidade e a seus direitos humanos universais. Infecções e a transmissão do HIV podem ser causadas pela falta de higiene dos procedimentos de MGF que são realizados por 'praticantes tradicionais' (correspondentes, em geral, às mulheres mais velhas das comunidades), sem anestesia e com objetos cortantes raramente es-

\footnotetext{
${ }^{9}$ Tradução das autoras do original em inglês.
} 
terilizados. Por vezes esses procedimentos ocasionam hemorragias que levam à morte, podendo ocorrer cortes acidentais dos tecidos adjacentes à zona operada (SACCHETTI, 2000).

Geralmente essas práticas são interpretadas como 'fundamentalismo religioso', 'coerção social' e 'opressão masculina', uma vez que são realizadas durante a infância e que, por isso, as mulheres são obrigadas a praticá-las. Entretanto, é importante ressaltar que esse conceito de infância é baseado em valores ocidentais e não leva em consideração o que as sociedades adeptas da Circuncisão Feminina consideram como infância e maioridade. Nessas sociedades, a passagem entre os grupos etários (como infância e maioridade) são definidos menos a partir da idade e mais em função de características adquiridas e demonstradas - como a capacidade sexual e reprodutiva, além de habilidades como força e responsabilidade. Assim, uma menina que menstrua aos oito anos já poderá ser considerada apta a passar para a maioridade através do ritual de iniciação que a tornará uma mulher. Além disso, a característica que delimitam a infância e a maioridade (deteminando o momento em que as meninas/mulheres serão iniciadas por meio de intervenções genitais) varia de acordo com a etnia e com o tipo de intervenção, podendo a prática ser realizada durante a primeira semana de vida, na idade de sete anos, durante a adolescência ou logo antes do casamento (BOTTI, 2007).

Com base na definição de Mutilação Genital Feminina (MGF) fornecida pela OMS, passaram a ser elaborados vários tratados internacionais voltados para o combate dessa prática, entre os quais o mais emblemático é o Protocolo de Maputo (AFRICAN UNION, 2003), assinado e adotado por mais de 15 países africanos em 2005. Baseado no marco jurídico estabelecido por esses tratados, em diversos países (na África e fora do continente), legislações nacionais começaram a ser emanadas proibindo a MGF e prevendo políticas públicas para contrastá-la. 
Embora o termo Mutilação Genital Feminina seja o mais utilizado, ele é contestado, em função da sua conotação excessivamente negativa e etnocêntrica, levando muitos autores, como Shell-Duncan \& Hernlud (2000), a defenderem o retorno à fórmula Circuncisão Feminina (CF), que era utilizada antes do termo MGF ser cunhado. Por sua vez, entre as pessoas que combatem a Mutilação Genital Feminina estão inúmeras mulheres que se definem como 'vítimas de $\mathrm{MGF}$ ', tendo realizado a prática obrigadas. Finalmente, combatem a Mutilação Genital Feminina também aqueles que compartilham do argumento feminista, segundo o qual a MGF seria uma violência sobre as mulheres e uma ameaça à sua dignidade - isto é, ao seu reconhecimento enquanto indivíduo dotado de 'direitos humanos universais' (MARTINGO et al., 2007).

A oposição entre os significados implicados no uso dos termos MGF, por um lado, e Circuncisão Feminina (CF), por outro, corresponde em larga medida à oposição entre os pontos de vista que estão em enfrentamento no impasse acerca da MGF. Contudo, nenhum desses dois termos esgota a diversidade das formas de Intervenção Genital Feminina (IGF) - pois deixam de fora a Cirurgia de Correção Genitália (CCG) e a Cirurgia 'Cosmética' Genital Feminina (CCGF), entre outras. Dessa forma, no presente texto, optou-se por utilizar o termo Intervenções Genitais Femininas (IGF) para tentar dar conta da diversidade das modalidades de intervenções realizadas nos órgãos genitais femininos e, assim, tentar encontrar uma via analítica que permita refletir criticamente sobre o impasse em torno da MGF e sobre as possibilidades de conciliação entre particularismos e universalismos.

\section{Impasses no C entro de Ref erência das M GFs em Florença, Itália}

Na União Europeia, a Itália é um dos países com maior índice da prática definida como Mutilação Genital Feminina (MGF) - 
relacionada ao alto número de mulheres imigrantes provenientes da Somália e da Eritréia, países em que a prática é extremamente difundida. Em 9 de janeiro de 2006, foi introduzida na legislação italiana uma lei que lança mão de políticas públicas e de sanções penais de modo a combater a prática definida pela OMS como MGF.

A lei italiana 7/2006 (ITÁLIA, 2006), além de criminalizar a Mutilação Genital Feminina (proibindo-a e instituindo uma série de punições para aqueles que a praticam) determina a realização de campanhas educativas para prevenir e enfrentar a MGF; prevê a adoção de estratégias de ação com o objetivo de informar à população italiana e aos imigrantes acerca dos riscos envolvidos na Mutilação Genital Feminina e também dos direitos das mulheres e crianças; por fim, a lei garante tratamento médico para as mulheres vítimas de MGF, assistência psicológica e acompanhamento durante a gravidez e o parto. Atualmente, essas políticas públicas são colocadas em prática a partir das diretrizes fornecidas pelo Ministério da Saúde Italiano e as principais ações são gerenciadas pelo INMP (Instituto Nacional pela Promoção da Saúde das Populações Migrantes e pelo Contraste das Doenças da Pobreza).

O Centro Regional de Referência para a Prevenção e Cura das Mutilações Genitais Femininas e das suas Complicações é uma das instituições que buscam colocar em prática as políticas públicas italianas voltadas para o combate da prática que eles denominam de MGFs. Com sede no Departamento de Ginecologia e Obstetrícia da Universidade de Florença, há mais de vinte anos o Centro recebe e trata mulheres provenientes de contextos islâmicos africanos, sem denunciá-las caso elas tenham realizado a prática que o Centro denomina de Mutilações Genitais Femininas (no plural). 0 Centro de Referência desenvolve atividades voltadas principalmente para o acompanhamento ginecológico e obstétrico de mulheres com MGFs. Sua estratégia de ação consiste em recrutar pacientes em centros religiosos e comunitários em Florença, apresentando o instituto e construindo rela- 
ções de confiança com os casais antes de realizar exames físicos ou operações, oferecendo inclusive a possibilidade das mulheres realizarem operações de reversão das Mutilações Genitais Femininas. Além disso, o Centro realiza uma série de pesquisas sobre as MGFs, seu significado e sua importância, assim como sobre a possibilidade de operações de reversão e sobre as implicações físicas e psicológicas, seja das MGFs, seja das operações de reversão. Desde 2007, ele atua em parceria com o INMP, desenvolvendo atividades alinhadas com as diretrizes do Ministério da Saúde Italiano (ITÁLIA, 2007).

Segundo Deninston et al. (2006) muitas mulheres recebidas no Centro de Referência de Florença, após serem informadas sobre os riscos das Mutilações Genitais Femininas (MGFs) e sobre a existência de operações de reversão, levantam a possibilidade de realizar uma Intervenção Genital Feminina mais branda como ritual de iniciação (para suas filhas, para si mesmas ou para as demais mulheres a serem iniciadas). Outras afirmam que gostariam de realizar o ritual de iniciação em hospitais, como no Centro de Referência de Florença, fazendo uso de instrumentalização asséptica, sendo assistidas por médicos - desde que mulheres - e acompanhadas por 'praticantes tradicionais'. Outras, ainda, pensam sobre a possibilidade de realizar uma cirurgia de reversão após casar-se, de modo a evitar a dor na primeira relação sexual, na gravidez e em exames ginecológicos. Assim, os autores apontam para os processos de mudança postos em ato pelas atividades do Centro e também para a existência de dois movimentos, aparentemente antagônicos. Diversas mulheres atendidas no Centro se dizem 'vítimas de Mutilação Genital Feminina' e são contrários à prática. Ao mesmo tempo, porém, várias mulheres atendidas no Centro de Referência de Florença afirmam a importância da prática e a defendem, sendo contrários à sua proibição e criminalização.

No Centro de Referência de Florença, portanto, diferentes posições acerca da MGF parecem se contrapor e se sobrepor, 
colocando em cheque qualquer pressuposto inicial acerca de uma oposição simples entre italianos favoráveis à criminalização da MGF, de um lado, e migrantes islâmicos africanos contrários a ela, de outro lado. Opiniões contrapostas são expressas pelos próprios migrantes, que ora defendem a importância de tipos específicos de Intervenção Genital Feminina (os quais passaram a ser definidos como Mutilação Genital Feminina), ora os concebem como uma violência, uma agressão física e também moral.

Quando vista como uma violência, a MGF pode ser pensada à luz da noção de 'insulto moral', formulada por Luís Roberto Cardoso de Oliveira $(2004,2005)$, ao analisar conflitos gerados em torno da demanda por direitos não universalizáveis. 0 autor sustenta que há um conjunto de direitos situados na interseção entre os universos da legalidade e da moralidade: as demandas por reconhecimento - fruto, nos termos dele, da transformação moderna da noção de honra em dignidade. Assim, no mundo ocidental contemporâneo, a ausência de expressões de reconhecimento pode ser percebida pelas pessoas como agressão moral, a qual é tratada pelo autor através da noção de 'insulto moral' - uma agressão que não pode ser traduzida materialmente e implica na desvalorização do outro enquanto pessoa moral.

Efetivamente, a Mutilação Genital Feminina (MGF) introduz uma genitália não prevista pelos padrões biomédicos, sendo vivenciada por muitos homens e mulheres, italianos e migrantes (inclusive mulheres de origem islâmica africana) como uma 'mutilação' violenta, que lesa a qualidade de vida da mulher, seus direitos humanos universais e sua dignidade. Assim, a MGF pode ser percebida como um insulto moral, ou seja, uma violência acrescida por um tipo especial de dor, a humilhação, decorrente do não reconhecimento e da desvalorização da pessoa moral posta em jogo pela Mutilação Genital Feminina (MGF): uma mulher privada de direitos humanos universais ao ter tido seus órgãos genitais 'mutilados'. 
Entretanto, outras posições expressas no Centro de Referência de Florença acerca da MGF sugerem que a criminalização da MGF também corresponde a uma violência. Com efeito, tipos específicos de Intervenção Genital Feminina (IGF) passaram de um segredo ritual valorizado a uma prática criminalizada e, assim, se transformaram em uma prática reivindicada, um direito pelo qual se deve lutar. Nesses casos, a Intervenção Genital Feminina (IGF) não parece ser vivenciada como uma violência, mas a definição da prática como Mutilação Genital Feminina sim e, especificamente, a criminalização da MGF, por parte da legislação (italiana e internacional). Efetivamente, a criminalização priva as mulheres de origem islâmica africana da possibilidade de transformarem-se em mulheres plenas, ferindo, assim, sua dignidade ao não reconhecer e desvalorizar a pessoa moral em questão: uma mulher incompleta, privada do direito de ter seus órgãos genitais genderificados e purificados. Mais uma vez, portanto, parece ser possível recorrer à noção de 'insulto moral', mas não para pensar a Mutilação Genital Feminina (MGF) e sim para pensar a proibição dela.

O duplo 'insulto moral' inerente ao debate sobre Mutilação Genital Feminina (MGF) parece instaurar uma situação paradoxal, na qual dignidades são feridas de ambos os lados, em nome da promoção, da garantia e da proteção de direitos humanos universais. Com efeito, a realização da intervenção na vagina agride a dignidade daqueles que as concebem como uma Mutilação Genital Feminina (MGF), enquanto a criminalização e proibição dessas práticas agride a dignidade daqueles que não as concebem como tal. Nesse sentido, seja a realização, seja a proibição dessa prática pode ser lida como um 'insulto moral', sendo ambas extremamente violentas para as partes envolvidas. Tal situação pode ser descrita recorrendo à noção de 'conflito moral', cujo único desenlace possível parece ser o aniquilamento, físico ou moral, de pelo menos uma das partes (Diniz, 2000). Conforme argumenta Débora Diniz (2000), o 'conflito moral' não pode ser solucionado contemplando plenamente os interesses discor- 
dantes. Nesse sentido, nem a retórica dos direitos humanos, nem o relativismo antropológico são plenamente capazes de resolver os conflitos entre lógicas e práticas culturais distintas. A retórica dos direitos humanos é problemática ao adotar uma postura moral fixa e tentar resolver os conflitos morais pela imposição de verdades absolutas. Por sua vez, o relativismo antropológico é igualmente problemático se corresponder à adoção de uma postura de tolerância radical que legitima a crença pela crença.

No entanto, o 'conflito moral' é intrínseco à relação com a alteridade e constitutivo da vida humana em sociedade - portanto ele é inevitável. Enquanto tal, o 'conflito moral' é constantemente manejado, ainda que não resolvido, sendo melhor, talvez, deixar de falar em 'resolução do conflito' para passar a nos referir à 'transformação dos conflitos' (SEGATO, 2000, p. 11) ${ }^{10}$. Seguindo essa sugestão, talvez seja possível lançar uma nova luz sobre essas questões, ao atentar não apenas para a Circuncisão Feminina (CF) e para a Mutilação Genital Feminina (MGF), mas também para outras formas de Intervenção Genital Feminina (IGF) que não são criminalizadas, embora apresentem fortes dimensões de violência - como a Cirurgia de Correção Genitália (CCG) e a Cirurgia 'Cosmética' Genital Feminina (CCGF). Efetivamente, essa parece ser uma interessante maneira de seguir a sugestão de Segato (2000) e tentar transformar, ao invés de tentar resolver, o 'conflito moral' manifesto no impasse entre Circuncisão Feminina 'versus' Mutilação Genital Feminina - ou entre Intervenções Genitais Femininas (IGFs) valorizadas enquanto práticas rituais 'versus' Intervenções Genitais Femininas (IGFs) criminalizadas enquanto contrárias aos direitos humanos -, ou, ainda, entre o 'insulto moral' inerente ao combate à Mutilação Genital Feminina (MGF) 'versus' o 'insulto moral' inerente à prática da Mutilação Genital Feminina (MGF).

${ }^{10}$ Tradução das autoras do original em espanhol. 


\section{Construção das CCGs e da CCGF}

As cirurgias realizadas nos órgãos genitais femininos por médicos, com instrumentalização asséptica e com fins terapêuticos, não entram no conceito de Mutilação Genital Feminina (MGF) - conforme definido pela OMS. Assim, elas não são problematizadas, tampouco combatidas. Contudo, as Cirurgias de Correção Genital (CCGs), que são adotadas no tratamento de 'hermafroditas', são realizadas nos orgãos genitais de crianças. Nesse sentido, ainda que elas sejam realizadas por médicos, com instrumentalização asséptica e com fins terapêuticos, elas se aproximam às circuncisões - masculinas e femininas - que são realizadas, em contextos rituais de religiões islâmicas africanas, para transformar em homens e mulheres (adultos), pessoas e corpos (infantis) ainda não completamente genderizados.

As Cirurgias de Correção Genital (CCGs) são frequentemente acompanhadas por sentimentos de mutilação genital e de invasão corporal: "Muitas sofreram cirurgias destinadas a reduzir o tamanho de seu clitóris. Ninguém as perguntou. Ninguém as explicou o porquê [...] Vivem em culturas onde seus corpos são temidos, são corrigidos, são mutilados". (SANDRINE MACHAD0, 2006, p.15). As crianças diagnosticadas com 'anomalias de diferenciação sexual' são submetidas, desde os primeiros dias de vida, a Cirurgia de Correção de Genitália (CCG) e a tratamentos hormonais - ferramentas consideradas aptas a adequar os corpos intersex a um 'sexo verdadeiro' entre aquele masculino e feminino biomedicamente definido. Em inúmeros casos, essa normatização (prescrita a corpos cuja sexualidade varia em relação a um padrão de corporalidade específico) tem consequências violentas e violadoras, podendo acarretar em infecções e problemas psicológicos, assim como na perda de sensibilidade, do prazer sexual e da funcionalidade dos órgãos genitais - ameaçando a saúde e a qualidade de vida dos 'pacientes' (SANDRINE MACHADO, 2006). 
A Cirurgia de Correção de Genitália (CCG) não se enquadra na definição de Mutilação Genital Feminina (MGF), mas também apresenta dimensões violentas que deveriam ser combatidas pelos movimentos sociais, pelas ONGs e por instituições nacionais e internacionais. No Brasil, por exemplo, os casos comumente denominados de intersex são definidos como 'patologia' pela resolução 1.664/2003 do Conselho Federal de Medicina, a qual sanciona que a 'investigação' do 'sexo verdadeiro' deve ser 'precoce' e o 'tratamento' realizado em tempo hábil (Sandrine Machado, 2006). Portanto, no Brasil, as Cirurgias de Correção de Genitália (CCG) tendem a ser realizadas na infância, sendo o 'paciente' obrigado a realizá-las. Em outros países, porém, a legislação é diferente e as Cirurgias de Correção Genitálias são realizadas somente após a maioridade do 'paciente', quando este seria capaz de decidir. Nesse sentido, as Cirurgias de Correção de Genitália (CCG) são problematizadas em um debate internacional análogo ao da Mutilação Genital Feminina. Contudo, é importante ressaltar que tal debate diz respeito apenas ao fenômeno do 'hermafroditismo', logo as Cirurgias de Correção de Genitália (CCG) não são pensadas em conjunto com a Mutilação Genital Feminina - enquanto tipos de Intervenção Genital Femininas, conforme se propõe no presente paper.

Também a Cirurgia 'Cosmética' Genital Feminina (CCGF) é deixada à margem da discussão sobre Intervenção Genital Feminina (IGF), embora ela possa facilmente ser incluída como uma forma de Mutilação Genital Feminina (MGF). 0 termo Female Genital “Cosmetic" Surgery (em português, Cirurgia 'Cosmética' Genital Feminina) foi cunhado para nomear a prática popularizada após uma atriz pornô do sul da Califórnia, nos Estados Unidos, ter feito e divulgado um vídeo da sua operação de remodelamento genital em 2000 (BRAUN, 2005). Essa prática tem gerado inúmeras polêmicas médicas, uma vez que profissionais se deparam perante problemas éticos quando são proibidos de realizar a Mutilação Genital Feminina (MGF), mas autorizados a realizar esse tipo de cirurgias plásticas, atualmente voltadas exclusivamente para o público feminino. As mulheres que realizam esse 
tipo de Intervenção Genital Feminina (IGF) reconstroem o hímen, modificam o volume ou o tamanho dos pequenos ou dos grandes lábios vaginais, do clitóris ou do púbis. Por motivos que essas mulheres definem como 'razões puramente estéticas', são praticadas cirurgias genitais, as quais eventualmente geram infecções ou acarretam na perda de sensibilidade, do prazer sexual e da funcionalidade dos órgãos genitais.

\section{Conclusão}

A adoção do termo Intervenção Genital Feminina (IGF), proposta neste trabalho, possibilita que a Circuncisão Feminina (CF), a Mutilação Genital Feminina (MGF), as Cirurgias de Correção de Genitália (CCG) e a Cirurgia 'Cosmética' Genital Feminina (CCGF) sejam pensadas em conjunto, permitindo atentar para o que há, ou não, de violento em cada uma delas. Nesse sentido, pode ser particularmente iluminador sair da dicotomia entre Circuncisão Feminina (CF) e Mutilação Genital Feminina (MGF) e comparar, de um lado, a Mutilação Genital Feminina (MGF) em oposição à Cirurgia 'Cosmética' Genital Feminina (CCGF) e, de outro lado, a Circuncisão Feminina (CF) em oposição às Cirurgias de Correção de Genitália (CCG).

A Mutilação Genital Feminina (MGF) é definida pela OMS como uma violência por ser realizada [1] sem fins terapêuticos ou com fins estéticos. Entretanto, ela parece ser particularmente violenta por ser realizada $[\mathrm{A}]$ na infância $\mathrm{e}[\mathrm{B}]$ em descumprimento às regras sanitárias. Efetivamente, [A] e [B] estão relacionadas a outros argumentos acionados para frisar a dimensão de violência presente na Mutilação Genital Feminina: tal prática ameaça [I] a saúde da mulher (podendo causar infecções, problemas psicológicos, doenças, e mortes); ela ameaça também [II] sua qualidade de vida (limitando seu prazer sexual genital); as mulheres realizam tal prática [III] por serem obrigadas - sendo a Mutilação Genital Feminina (MGF) descrita em termos de 'submissão feminina', 'opressão masculina', 'fundamentalismo religioso', 'coerção social' etc. 
Por sua vez, a Cirurgia 'Cosmética' Genital Feminina (CCGF) não é definida como uma violência embora seja realizada [1] sem fins terapêuticos e com fins estéticos. A esse respeito é importante ressaltar que embora a Cirurgia 'Cosmética' Genital Feminina (CCGF) não seja realizada [A] na infância, nem [B] em descumprimento às regras sanitárias, ela ameaça [I] a saúde da mulher e [II] sua qualidade de vida (podendo limitar o prazer sexual genital e causar doenças). Além disso, é difícil afirmar se as mulheres realizam ou não a prática [III] obrigadas, uma vez que a Cirurgia 'Cosmética' Genital Feminina (CCGF) é realizada em função de um padrão estético de gênero culturalmente vigente.

No que tange à Circuncisão Feminina (CF) e à Cirurgia de Correção de Genitália (CCG), ambas apresentam dimensões de violência, embora apenas a primeira seja comumente definida enquanto tal. Nesse ponto, chama a atenção o fato de que ambas são realizadas [A] na infância, mas apenas a Circuncisão Feminina $(\mathrm{CF})$ é realizada [B] em descumprimento às regras sanitárias. Ainda assim, ambas ameaçam [I] a saúde da mulher e [II] sua qualidade de vida (podendo limitar o prazer sexual genital e causar doenças), sendo particularmente difícil afirmar se as mulheres realizam (ou não) essas duas práticas [III] obrigadas. É igualmente difícil sustentar se ambas as práticas são, ou não, realizadas [1] sem fins 'terapêuticos' ou com fins estéticos. Efetivamente, as duas práticas são realizadas com fins estéticos que são também 'terapêuticos': ambas são realizadas à maneira dos padrões de corporalidade vigentes, os quais são etnocêntricos nos dois casos - biomedicamente específicos no que tange à Cirurgia de Correção de Genitália (CCG) e ritualmente específicos no que tange à Circuncisão Feminina (CF).

A definição fornecida pela OMS (WHO, 1997) de Mutilação Genital Feminina (MGF) traz em si uma perigosa ambiguidade, ao pressupor uma diferença absoluta entre fins 'terapêuticos' e fins estéticos. De fato, a comparação entre Mutilação Genital Feminina (MGF), Cirurgia 'Cosmética' Genital Feminina (CCGF), Circun- 
cisão Feminina (CF) e Cirurgia de Correção de Genitália (CCG) revela que essa diferença é relativa e, mais que isso, demonstra que a visão de Humano é genderificada e supõe um ideal estético (o qual mescla a materialidade dos corpos com representações sociais associadas ao masculino ou ao feminino). Nesse sentido, a comparação entre essas quatro formas de Intervenção Genital Feminina (IGF) sugere que seu aspecto violento não reside no fato delas serem ou não serem realizadas [1] sem fins terapêuticos e com fins estéticos, tampouco no fato das mulheres serem ou não serem [III] obrigadas a realizá-las.

Esses dois fatores (1 e III) estão diretamente relacionado às recorrentes descrições da Intervenção Genital Femininas (IGF) em termos de 'submissão feminina', 'opressão masculina,' 'fundamentalismo religioso', 'coerção social', mas apresentam um grave problema analítico. Eles estão ancorados no falso pressuposto de que cada cultura e cada gênero corresponde a uma entidade monolítica fixa e unitária, isto é, a uma totalidade imaginada como uniformatada, internamente homogênea e dotada de fronteiras definidas, rigidamente estabelecida em torno de uma legitimidade, sem quaisquer fraturas. Esse mesmo pressuposto postula a existência de formas universais de dominação e de violência entre culturas e entre gêneros. No entanto, a atribuição de sentidos de (não) violência depende dos cenários das práticas específicas, da diversidade cultural e também da posição diferenciadas dos agentes, ou seja, depende dos valores diferenciais atribuídos ao gênero (assim como à geração, à proximidade etc.) por parte das pessoas que fazem ou sofrem a ação (Zanotta Machado, 2013). Nesse sentido, é dificil descrever a Circuncisão Feminina (CF) ou a Mutilação Genital Feminina (MGF) em termos absolutos de 'fundamentalismo religioso' e de 'submissão feminina', uma vez que se trata de uma prática realizada em mulheres, por mulheres, estando relacionada às sociedades secretas femininas presente em contextos islâmicos específicos do continente africano. Analogamente, é difícil descrever ambas - e as Cirurgias de Correção de Genitália (CCG) e a Cirurgia 'Cosmética' Genital Feminina (CCGF) - em termos ab- 
solutos de 'fundamentalismo religioso', 'submissão feminina' e 'coerção social', já que se trata de práticas marcadas por sentidos ambíguos, emoções contraditórias e ambivalências morais.

Portanto, a argumentação desenvolvida no presente artigo sugere que o aspecto violento, identificado em todas as formas aqui analisadas de Intervenção Genital Feminina (IGF), decorre do fato de esta ser realizada, ou não, [A] na infância e/ou [B] em descumprimento às regras sanitárias. Além disso, o aspecto violento das IGF está relacionado a um fator que não problematizado é pela definição de MGF: o fato da IGF ser realizada [C] em um grau (tamanho ou tipo) que limita o prazer sexual genital. Esses três fatores (A, B e C) ameaçam [I] a saúde da mulher e/ou [II] sua qualidade de vida (podendo limitar o prazer sexual genital e causar doenças). Uma vez que esses três fatores não são exclusivos da Mutilação Genital Feminina - mas também estão presentes (em certa medida) na Circuncisão Feminina (CF), nas Cirurgias de Correção de Genitália (CCG) e na Cirurgia 'Cosmética' Genital Feminina (CCGF) - a violência inerente a esses fatores não podem ser combatida por meio de legislações (internacionais e nacionais, como a italiana) que criminalizam, sempre e apenas, a Mutilação Genital Feminina (MGF). Ao limitar-se a uma crítica das práticas alheias de violação dos direitos humanos, tais legislações fecham os olhos para as próprias violações desses mesmos direitos e dão margem a uma série de contradições, gerando novas violências, inclusive sob a forma de 'insultos morais'.

Diferentemente, esses três fatores podem ser minimizadas por meio de legislações que regulamentem o fenômeno da Intervenção Genital Feminina (IGF) como um todo, combatendo certas condições de realização da prática - ou seja, combatendo a realização da IGF $[\mathrm{A}]$ na infância e/ou [B] em descumprimento às regras sanitárias e/ou [C] em um grau (tamanho ou tipo) que limita o prazer sexual genital. De fato, legislações como essas podem ser capazes de conscientizar as pessoas acerca da importância que a Intervenção Genital Feminina (IGF) pode ter, do direito que a mulher pode ter 
de realizá-la e também das ameaças que ela pode representar para [I] a saúde da mulher e/ou [II] sua qualidade de vida.

Em suma, o presente artigo defende a importância de refletir criticamente sobre os aspectos violentos presentes em todas as IGFs (não apenas na MGF) e de combatê-los. Entretanto, a posição assumida pelas três autoras deste texto é contrária à proibição da MGF (ou de qualquer Intervenção Genital Feminina), pois além da criminalização ser uma alternativa violenta e estigmatizante, ela parece ser simplesmente ineficaz. 0 que nos parece fundamental é introduzir políticas públicas (campanhas de conscientização, espaços para debate, centros de apoio etc.) que sejam efetivamente capazes de reduzir os aspectos violentos (A, $\mathrm{B}$ e C) presentes em todas as IGFs.

\section{Ref erências}

AFRICAN UNION. Protocol to the African charter on human and people's rights on the rights of Wemen in Africa: Maputo Protocol. Maputo, 2003. Disponível em: <http://www.achpr.org/files/instruments/women-protocol/achpr_instr_proto_women_eng.pdf $>$. Acesso em: 18 jun. 2015.

BOTTI, Federica. L'escissione femminile tra cultura ed etica in Africa. 2007. 258f. Tese (Doutorado em Bioética) - Alma Mater Studiorum, Università per gli studi di Bologna.

BRAUN, Virginia. In search of (better) sexual pleasure: female genital 'cosmetic' surgery. Sexualities, v. 8, n. 4, p. 407-424. 2005.

CARDOSO DE OLIVEIRA, L.R. Direitos, insultos e cidadania (Existe violência sem agressão moral?). Série antropologia, 371. Brasília: UnB, 2005.

DENINSTON, Gerge C. et al. Bodily integrity and the politics of circumcision. Culture, controvery and change. New York: Springer, 2006.

DINIZ, Débora. Antropologia e os limites dos Direitos Humanos: o dilema moral de Tashi. In: NOAVAES, R.; KANT de LIMA, R. (Org). Antropologia e Direitos Humanos. Eduff: Niterói, 2000.

LA MONACA, Giuseppe; AUSANIA, Francesco., SCASSELLATI SFORZOLINI, Giovanna. Le mutilazioni genitali femminili. Aspetti socio-antropologici, e medico 
legali e contributo casistica. Rivista italiana di medicina legale, v. 3-4, 2004, p.641-670. 2000.

LIGHTFOOT-KLEIN, Hanny. Prisioner of ritual: an odyssey into female genital circuncision in Africa, 1989.

MACCORMACK, Carol, P. Sande: The Public Face of a Secret Society. In: JULES-ROSETTE, BENNETTA (Org.), The New Religions of Africa. Norwood, New Jersey, 1979.

MARTINGO, C. et al. Por Nascer Mulher... um outro lado dos Direitos Humanos. Lisboa : APF, 2007.

ITÁLIA. Legge 9 gennaio 2006, n. 7. Disposizioni concernenti la prevenzione e il divieto delle pratiche di mutilazione genitale femminile. Gazzetta Ufficiale n. 14, 18 gennaio, 2006. Disponível em: <http://www.camera.it/parlam/ leggi/06007l.htm>. Acesso em: 18 jun. 2015.

ITÁLIA. Linee guida del Ministro della Salute sulle Mgf per l'anno 2008. Linee guide destinate alle figure professionali sanitarie che operano con le comunità di migranti... Conferenza Stato-Regioni nella seduta del 20 settembre 2007. Disponível em: <http://www.salute.gov.it/imgs/c_17_pubblicazioni_769_allegato.pdf>. Acesso em 18 jun. 2015.

SACCHETTI Graziella, Gli aspetti medici e ostetrico-ginecologici. In: MAZZETTI M., Senza le ali: le mutilazioni genitali femminili. Milano: Franco Angeli, 2000. p. 79-86.

SANDRINE MACHADO, Paula. No Fio da Navalha: Reflexões em torno da Interface entre intersexualidade, (Bio)Ética e Direitos Humanos. In: GROSSI, M., HEILBORN, L. e MACHADO, L. (Orgs.) Antropologia e Direitos Humanos 4. Florianópolis: ABA e Nova Letra Ed., 2006.

SEGATO, Rita Laura. Antropología y derechos humanos: alteridad y ética en el movimiento de los derechos universales. Série Antropologia, n.356. Brasília: UnB, 2004.

SHELL-DUNCAN, Bettina; HERNLUND, Yilva. Female "'circumcision"' in Africa: culture,controversy, and change. Boulder, Colorado: Lynne Rienner Publishers, 2000.

WHO/UNICEF/UNFPA. Female Genital Mutilation: A Joint WHO/UNICEF/ UNFPA Statement. Genova: World Health Organization, 1997. Disponível em: <http://www.childinfo.org/files/fgmc_WHOUNICEFJointdeclaration1997. pdf>. Acesso em: 18 jun. 2015.

ZANOTTA MACHADO, Lia. Feminismo em Movimento. São Paulo: Edit. Francis, 2013.

Recepção dos artigos: 30/06/2015

Data de aprovação 30/07/2015 